[Aus dem hygienischen Institut der Universität Breslau.]

\title{
Ueber den Einfluss der Ventilation auf in der Luft suspendirte Mikroorganismen.
}

Von

Dr. med. Richard Stern.

Die Untersuchung der in der Luft enthaltenen Mikroorganismen ist in den letzten Jahren von einer grösseren Anzahl von F'orschern in Angriff genommen worden; besonders hat die Benutzung der von Koch eingefübrten bacteriologisehen Methoden eine genauere und bequemere quantitative Bestimmung des Keimgehaltes der Luft ermöglicht (Methoden von Hesse ${ }^{1}$ und Petri ${ }^{2}$ ). Auf diese Weise sind wir über die durchschnittliche Grösse desselben im Freien, auf den Strassen, in bewohnten Räumen, speciell auch in Krankenhäusern unterrichtet worden; weiterhin wurde von verschiedenen Forschern, besonders von Miquel ${ }^{3}$ und Frankland, ${ }^{4}$ der Einfluss der Jahreszeit, der Windrichtung u. s. w. auf den Keimgehalt der Atmosphäre geprüft; und selbst die Luft auf hohen Bergen und über fernen Meeren ist auf ihren Bacteriengehalt untersucht worden.

Merkwürdiger Weise wurde indess diejenige Frage, welche das nächstliegende praktische Interesse darbietet, die Frage nämlich: wie lässt sich die Luft unserer Wohnräume, speciell unserer Krankenzimmer, keimfrei machen bezw. erhalten? bisher verhältnissmässig wenig bearbeitet. Zwar

1 W. Hesse, Ueber quantitative Bestimmung der in der Luft enthaltenen Mikroorganismen. Mittheilungen aus dem Kaiserl. Gesundheitsamt. 1884. Bd. II. S. $182 \mathrm{ff}$.

2 R. Petri, Eine neue Methorle, Bacterien und Pilzsporen in der Luft nachzuweisen und zu zählen. Diese Zeitschrift. 1888. Bd.III. S. $1 \mathrm{ff}$.

${ }^{3}$ Annuaire de Montsouris. 1879 u. folg. Jahre.

4 Frankland, The distribution of Microorganisms in Air und Frankland and Hart, Further experiments on the distribution etc. Proceedings of the Royul Society. 1886. (Anwendung der Hesse'schen Methode.) 
besitzen wir bereits eine ganze Reihe von Untersuchungen über die Dosinfection von Wohnräumen durch gas - oder dampfförmige Antiseptica; aber hierbei ist niemals der Einfluss der Ietzteren auf wirklich in der Luft suspendirte Keime geprüft worden, sondern man hat Seidenfäden, Gartenerde u. dgl., an denen Bacterien oder Kokken eingetrocknet waren, an verschiedenen Stellen eines Zimmers hingelegt und dann die Desinficientien auf dieselben einwirken lassen.

Auch wenn wir davon absehen, dass diese Versuchsanordnung eine etwas unvollkommene Nachahmung der natürlichen Verhältnisse ist, so kann es sich doch überhaupt bei all' diesen Versuchen nur um die Desinfection von solchen Zimmern handeln, die während des betreffenden Verfahrens jeglicher Benutzung entzogen sind. Die continuirliche Entfernung der Keime aus dauernd bewohnten Räumen, speciell also auch aus Krankenzimmern, kann natürlich auf diesem Wege nicht erreicht werden; diesem Zwecke soll vielmehr, nach der wohl allgemein herrschenden Anschauung, die Ventilation dienen: sie soll die durch Loslösung vom Fussboden, von den Kleidern, vom Körper der Kranken u. s. w. in die Luft gelangenden Keime baldigst wieder aus derselben entfernen und somit - ausser der Fortschaffung der gasförmigen Stoffwechsel- and Zersetzungsproducte - noch eine zweite, in hygienischer Beziehung fast noch wichtigere Aufgabe erfüllen: etwaige in der Luft suspendirte Infectionstrïger zu beseitigen.

Dieser letztere Gesichtspuukt hat denn auch wohl ohne Zweifel viel dazu beigetragen, dass jetzt bei der Anlage nener Krankenhäuser der Herstellung einer möglichst ausgiebigen Ventilation erhöhte Bedeutung beigelegt wird.

Ob nun aber jene ",desinficirende" Wirkung der Ventilation wirklich zukommt, ist bisher noch nicht experimentell untersucht worden. ${ }^{1}$ Auf Veranlassung von Hrn. Prof. Flügge und unter seiner Leitung habe ich deshalb während des verflossenen Winters im Breslauer hygienischen Institute diesbezügliche Versuche angestellt.

Dabei musste natürlich zunächst ermittelt werden, wie sich die von uus suspendirten Keime verhalten, wenn sie von Luftströmungen nicht

${ }^{1}$ Nur Neumann (Ueber den Keimgehalt der Luft im städtischen Krankenhause Moabit in Berlin, Vierteljahrsschrift für gerichtliche Medicin und äffentliches Sanitätswesen, 1886, Bd. XIV, S.312) erwähnt beiläufig, dass bei einem Theil seiner Beobachtungen (nämlich bei den zar Nachtzeit angestellten) darauf geachtet wurde, "ob die Ventilation den Pilzgehalt der Luft in irgend einer Richtung beeinflusse." "Während der Untersuchung sank die lialte Luft häufig ans den oberen Luftklappen mit Erzeugung eines mässig starken Zuges in rlen Mittelgang, wo der Apparat in Gang war, hinab; trotzdem zeigte sich keine deutliche Beeinflussung der Keimmenge durch die Ventilation." 
beeinflusst werden. Ausser auf die Wirkung der Ventilation haben sich dann meine Versuche noch auf einige naheliegende Fragen erstreckt; namentlich wurde untersucht, ob die Entwickelung von Wasserdampf in der Luft schwebende Mikroorganismen rasch niederschlägt: ferner, ob die bei der Ventilation auftretenden Iuftströmungen im Stande sind, Keime vom Fussboden, Tapeten, Kleiderstoffen u. s. w. abzulösen.

Die Thatsachen, welche bisher bezüglich des Verhaltens der Mikroorganismen in der Luft bekannt geworden sind, und von denen eine experimentelle Nachahmung der natürlichen Verhältnisse ausgehen musste, lassen sich kurz in folgende Sätze zusammenfassen: ${ }^{1}$

I. Eine Loslösung der Bacterien von feuchten Oberflächen ist selbst durch starke Luftströmungen - nicht möglich (Naegeli, Wernich u. A.).

II. Daher künnen Bacterien in lebensfähigem Zustande nur dann in die Luft gelangen, wenn sie das Eintrocknen vertragen.²

III. Die Loslösung der Keime findet im Allgemeinen nicht in isolirtem Zustande statt; gewöhnlich haften dieselben an Staubpartikelchen, und zwar meist durchaus nicht an Sonnenstäubchen oder den noch feineren, makroskopisch gar nicht sichtbaren Partikelchen, ${ }^{3}$ sondern an relativ gröberen Staubtheilchen. Oft finden sich auch zahlreiche, meist derselben Art angehörige Bacterien zu grösseren Complexen vereinigt (Hesse).

IV. Bei ruhiger Luft findet - entsprechend der Schwere ihrer staubförmigen Träger - ein mehr oder minder schnelles Absetzen der Keime statt. $^{4}$

V. Eine Vermehrung von Mikroorganismen findet in der Luft nicht statt, da es ihnen an der nöthigen Feuchtigkeit fehlt.

VI. In Uebereinstimmung mit den beiden zuletzt angeführten Thatsachen ergiebt sich aus den directen Beobachtungen von Hesse, Frank-

${ }^{1}$ Vgl. Flügge, Die Mikroorganismen. 1886. 2. Aufl. S.558. - Koçh, Die Bekëmpfung der Infectionskrankheiten, insbesondere der Kriegsseuchen. 1888. S. 19.

${ }^{2}$ Eine Ausnahme findet $d a$ statt, wo durch Verstäuben oder Verspritzen von keimhaltigen Flüssigkeiten kleine Wasserbläschen von Luftströmungen fortgeführt werden. Aber eine solche Fortführung erfolgt meist nur auf kurze Strecken und kann überhaupt nicht als ein wirklicher Uebergang von Keimen in die Luft angesehen werden.

${ }^{3}$ Vgl. die Classification von Naegeli (Untersuchungen über niedere Pilze, 1882) in seiner Arbeit: Ueber die Bewegungen kleinster Körperchen.

4 Koch giebt an (a. a. O., S. 20), dass dies auch bei einer Bewegung der Luft bis $\mathrm{zu} 0.2^{\mathrm{m}}$ in der Secunde stattfindet. 
land, Petri u. A., dass der Keimgehalt der Luft im Allgemeinen nur ein geringer ist; besonders gering ist derselbe im Freien, zumal bei feuchter Bodenoberfläche, und andererseits auch in solchen geschlossenen Räumen, in denen kein Staub aufgewirbelt wird.

Sollten die Ergebnisse unserer Untersuchungen für die Praxis verwerthbar sein, so musste sich die Anordnung der Experimente möglichst eng an die thatsächlichen Verhältnisse anschliessen. Mit Rücksicht hierauf war der Versuchsplan folgender:

In der Luft eines, mit ausgiebiger und beliebig abstufbarer Ventilation versehenen Zimmers wird bacterienhaltiger Staub möglichst gleichmässig vertheilt. Eine sofort nach dem Ende der Verstäubung vorgenommene, quantitative Bestimmung ergiebt den jetzt vorhandenen Keimgehalt der Luft: "die Aussaat". Darauf wird durch in bestimmten Intervallen wiederholte Bestimmungen die Abnahme der Keime bei ruhigem Absetzenlassen, bezw. bei Einwirkung der Ventilation in verschiedener Stärke, bezw. bei Entwickelung von Wasserdampf beobachtet. Aus dem Vergleich der bei den letzten beiden Versuchsreihen erhaltenen Resultate mit dem Ergebniss der ersten musste festzustellen sein, inwieweit die Ventilation oder die Entwickelung von Wasserdampf geeignet ist, die in der Iuft suspendirten Mikroorganismen schneller aus derselben zu entfernen, als dies durch die blosse Wirkung der Schwere geschieht.

Im Folgenden theile ich zunächst die Versuchsanordnung, dann die gewonnenen Resultate mit; zum Schluss werden die sich aus ihnen ergebenden Folgerungen zu besprechen sein.

\section{Yersuchs-Anordnung.}

\section{Das Versuchszimmer}

war ein zweifenstriges, im dritten Stockwerk des Hauses gelegenes Zimmer von $5.40^{\mathrm{m}}$ Länge, $5.55^{\mathrm{m}}$ Breite und $2.85^{\mathrm{m}}$ Höhe; sein Rauminhalt betrug demgemäss $85 \cdot 41 \mathrm{cbm}$.

Das Zimmer hatte zwei Thüren; die eine, der Fensterseite gegenüber gelegen, führte in den Treppenflur, die andere in ein Nebenzimmer, in welchem die für die Bestimmung des Keimgehaltes der Luft nothwendigen Aspiratoren untergebracht waren (s. u.). Die Thüren wurden durch Zwischennageln von Barchendstreifen gedichtet. An den Fenstern wurden die Schlussstellen der Rahmen mit Baumwollbarchend benagelt, dann die Fenster fest geschlossen und sämmtliche Fugen mit Glaserkitt überstrichen, und endlich noch die ganzen Fensterrahmen dick mit Oelfarbe gestrichen, 
Die Ventilation wurde folgendermaassen eingerichtet: Der Luftzufuhr dienten vier obere und vier untere quadratische Oeffnungen von je $20 \mathrm{om}$ Seitenlänge; sie lagen sämmtlich in der Wand der Fensterseite; die vier unteren wurden in gleichen Abständen dicht über dem Fussboden durch die Mauer gebrochen, mit Zinkblech ausgekleidet und mit einem Schutzgitter zur Abhaltung gröberen Staubes versehen. Behufs Herstellung der vier oberen Oeffnungen wurden die kleineren, oberen Flügel der beiden Fenster durch Blechplatten ersetzt, in welchen sich Oeffnungen von der angegebenen Grösse befanden; ihr unterer Rand lag in eimer Höhe von $2 \cdot 2^{\mathrm{m}}$ über dem Fussboden. Nach innen war bei jeder dieser Oeffnungen ein Ansatzrohr ron etwa $30 \mathrm{~cm}$ Länge angelöthet. Sämmtliche acht Oeffnungen waren an ihrer inneren Mündung durch gut aufpassende Deckel verschliessbar; auch liess sich mit Hülfe derselben ihr Querschnitt beliebig verkleinern.

Der Luftabfuhr dienten zwei Wasser- und drei Gasventilatoren, welche sämmtlich an bezw. in der den Fenstern gegenüberliegenden Wand angebracht waren; auf der einen Seite standen oben und unten die Wasserventilatoren, und zwar oben ein solcher mit rerticalem Flügelrad von Schüffer \& Walcker in Berlin, unten einer mit horizontalem Flügelrad von Dannenberg \& Quandt. Die Oeffnungen beider waren lireisförmig, die des oberen hatten einen Durchmesser von $16^{\mathrm{cm}}$, die des unteren einen solchen von $11.5 \mathrm{~cm}$. Auch diese Oeffnungen waren durch Deckel verschliessbar.

Auf der anderen Seite befanden sich zwei obere und eine untere in die Wand des Hauptschornsteines des Hauses gebrochene Oeffnungen, von deren unterem Rande besonders construirte Gasbrenner zur Erzeugung einer langen rauschenden Flamme schräg in das Innere des Schornsteins hineinragten. Die Maasse betrugen:

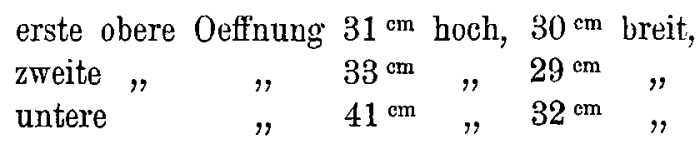

Alle drei Oeffnungen waren durch Klappen zu verschliessen bezw. in ihrem Querschnitt beliebig zu reduciren.

Die Leistungsfähigkeit dieser Ventilationsanlage war eine in jeder Beziehung zufriedenstellende. Sommerventilation (Einstrümung unten, Abströmung oben) und Winterventilation (Einströmung oben, Abströmung unten) liessen sich durch Veränderung der Grösse und Ziahl der Ein- und Ausströmungsöffinungen, durch Regulirung des 'Wasserzuflusses, resp. der Flammenhöhe bei den Ventilatoren in beliebiger Abstufung ihrer Intensitit herstellen. Behufs Messung der letzteren wurden bei jedem Ventilationsversuch 
Einfuuss der Ventilation aUf den Keimgehalt der Luft. 49

die Luftgeschwindigkeit ${ }^{1}$ in den zur Verwendung kommenden Ausströmungsoffinungen sowie der angewandte Querschuitt der letzteren bestimmt. War bei einem Versuche eine bestimmte Ventilationsgrösse wünschenswerth, so wurde die dazu erforderliche Anordnung vorher ausprobirt. Natürlich wurde wïhrend des eigentlichen Versuches nochmals nachgesehen, inwieweit die gewünschte Stärke des Luftwechsels erreicht war.

Die maximale Leistung unserer Ventilation - Oeffnung sämmtlicher acht Eintrittsöffnungen, maximale Wirkung der fünf Ventilatoren lieferte in einem Versuche $2250^{\text {cbm }}$ Luft in der Stunde, was einer etwa 27 maligen Erneuerung der Zimmerluft während dieser Zeit entspricht. -

Bei manchen Versuchen (s. unten) erschien es wünschenswerth, die Menge der auf den Fussboden niedergefallenen Keime annähernd kennen zu lernen. Man hätte zu diesem Zwecke einen bestimmten, kleinen Theil desselben mit einem Schwämmchen oder dergleichen abreiben, diesen in verflüssigtes Nährmaterial bringen und dann Platten giessen können.

Für unseren Zweck war indess folgender Weg einfacher und wohl mindestens ebenso genau: Auf eine quadratische Glisplatte (aus dickem Fensterglase) von ca. $8^{\mathrm{cm}}$ Seitenlänge wurde rings ein etwa $3^{\mathrm{mm}}$ hoher, $1^{\mathrm{cm}}$ breiter Holzrahmen mittelst Glaserkittes befestigt. In diesen Rahmen wurden mosaikartig neun quadratische Holatäfelchen von $2 \mathrm{~cm}$ Seitenlänge und ebenfalls $3 \mathrm{~mm}$ Höhe hineingelegt; um sie leicht neben einander einsetzen und ebenso leicht wieder einzeln herausnehmen zu können, war es zweckmässig, die Seitenflächen dieser Täfelchen nach unten zu etwas abzuschrägen. Die Holzart (Fichtenholz) und der Oelfarben-Anstrich waren dieselben, wie bei dem Fussboden des Versuchszimmers. Vor jedem Versuch wurden die Glasplatten und die Holztïfelchen in Sublimatlösung desinficirt, dann surgfältig in sterilem Wasser abgewaschen und zwischen sterilisirtem Filtrirpapier getrocknet. Aus dem Fussboden des Zimmers wurden an neun verschiedenen Stellen Löcher von entsprechender Ausdehnung und Tiefe ausgestemmt, derart, dass, wenn man die Glasplatten mit den darauf befindlichen Holztäfelchen hineinsetzte, die Oberfläche der letzteren mit dem übrigen Fussboden in demselben Niveau lag.

Wollte man nun die Menge der auf den Fussboden niedergefallenen Keime, eventuell auch eine etwaige Zunahme oder Abnahme derselben im Laufe eines Versuches bestimmen, so brauchte man nur mit einer geglühten Nadel eines oder mehrere dieser Täfelchen vorsichtig herauszuheben und jedes derselben in eine daneben hingestellte Culturschale hinein-

${ }^{2}$ Die Bestimmung derselben geschah durch Flügelrad -Anemometer von Fuess (Berlin). Die vier angewandten Instrumente zeigten unter sich wie auch bei Vergleichung mit eivem Recknagel'schen Anemometer eine befriedigende Uebereinstimmung.

Zeitsehr. f. Hygiene. VII. 
zulegen. In dieser wurde dasselbe später mit dem verflüssigten Nährmaterial übergossen und die anhaftenden Keime durch Umherziehen des Täfelchens (mittels einer vorher durch Glühen sterilisirten Pincette) abgelöst; obgleich dies, wie die Erfahrung zeigte, leicht und vollständig gelang, so liess ich doch das Täfelchen selbst in der Schale, um etwa noch an demselben haften gebliebenen Keimen Gelegenheit zum Auswachsen zu geben.

Vor Beginn der Versuche wurde das Zimmer gereinigt und desinficirt: die Decke frisch gekalkt, Fussboden und Tapeten, sowie die Eintrittsöffnungen für die Luft mit $1 \%$ Sublimatlösung abgewaschen. Aus den weiter unten zu besprechenden Ergebnissen unserer Versuche folgt, dass eine Desinfection des Zimmers durchaus nicht etwa vor jedem neuen Versuche erforderlich ist. Nothwendig wird dieselbe nur dann, wenn die Art des zur Verstäubung kommenden Materials gewechselt wird.

\section{Die Auswahl des Verstäubungs-Materials.}

Nach den oben zusammengestellten bisherigen Erfahrungen über das Verhalten der Mikroorganismen in der Luft sind wir zu der Annahme berechtigt, dass anch diejenigen pathogen en Mikroorganismen, welche das Austrocknen vertragen und bei welchen somit die Möglichkeit einer Luftinfection vorliegt, an Staubpartikelchen haften. Je feiner diese Partikelchen sind, desto länger werden sie in der Luft suspendirt bleiben, desto länger wird mithin auch die Gefahr einer Infection bestehen. Es wäre aber, wie ebenfalls schon oben erwähnt, ein Irrthum, anzunehmen, dass gerade die kleinsten Staubnartikelchen (so fein wie Sonnenstäubchen oder noch feiner) dje Träger der Mikroorganismen seien.

Wollten wir nun die natürlichen Verhältnisse möglichst getreu nachahmen, so konnten wir dies kaum auf einem anderen Wege erreichen, als indem wir den Staub aus Zimmern, in denen viele Menschen verkehren, benützten. Der Crsprung dieses Staubes ist natürlich ein höchst mannigfaltiger; er besteht zum Theil aus kleinen Erdpartikelchen, die ron den in das Zimmer gelangenden Menschen mit Schuhen und Kleidern hereingebracht werden; ferner aus feinen Fäserchen pflanzlicher und thierischer Herkunft, die sich von den verschiedenen Kleidungsstücken loslösen; ein anderer Theil des Staubes ist dureh Fenster und Thüren von der Strasse u. s. w. hineingelangt und seine Zusammensetzung wird demnach von den verschiedensten äusseren Umständen abhängen.

Nun ist freilich ein sehr beträchtlicher Theil dieses Staubes zur Vermittelung einer Luftinfection nicht geeignet; die grösste Menge des gewöhnlichen Stubenkehrichts ist zu schwer, um selbst nur kürzere Zeit in der Luft schweben zu bleiben. Für unsere Verstäubungsversuche war es 
zweckmässig, von vornherein diese schwereren Antheile des Staubes möglichst auszuschliessen. Dies liess sich bis zu einem gewissen Grade erreichen, indem wir nicht den eigentlichen Kehricht, sondern nur solchen Staub, der sich in einer Höhe ron mindestens $2^{m}$ abgelagert batte, benützten. Von diesem Material konnte man von vornherein mit Sicherheit annehmen, dass es zum Theil aus solchen Staubtheilchen besteht, welche längere Zeit in der Iuft geschwebt haben. Da für unsere Experimente, bei denen ein ganzes Zimmer mit Staub erfüllt werden sollte, grössere Mengen desselben erforderlich waren, so kam es darauf an, einigermassen ergiebige Fundorte für denselben zu ermitteln. Als solche erwiesen sich nun die oberen Flächen der Schränke und die Lampenschirme in manchen Schulen. Von ihnen habe ich denn auch den grössten Theil des Versuchsmaterials entnommen. ${ }^{\perp}$ Beim Abkehren des Staubes musste natürlich sehr behutsam verfahren werden, weil sonst ein grosser Theil des feinsten und für uns werthvollsten Materiales in die Luft übergegangen wäre; ganz und gar lässt sich dies allerdings nicht vermeiden.

Das so gewonnene Material war nun in der That zu einem Theile recht fein; der leiseste Anstoss genügte, um eine kleine Wolke desselben sich erheben zu lassen, beim Verstäuben bemerkte mar, dass ein Theil desselben nur bei directer Beleuchtung durch die Sonne sichtbar wurde, also in der 'That die Feiuheit von Sonnenstäubchen hatte; ebeuso kounte man freilich sehen, dass ein anderer Theil sich rasch zu Boden senkte.

Bei der grossen Wichtigkeit, welche die Auswahl des Verstäubungsmaterials für die Tragweite unserer Versuche hatte, schien es geboten, auch noch andere Staubsorten zu versuchen. Ich verschaffte mir deshalb sogenannten „Hadernstaub" aus einer Papierfabrik, sowie Staub aus den Arbeitsräumen einer Filzhutfabrik. Beide Staubsorten enthalten zunächst sehr viele gröbere Theilchen beigemischt. Um eine Sonderung des feinsten Materials zu bewirken, wäre ein einfaches Durchsieben des Staubes kaum hinreichend gewesen; denn es kam für unsere Zwecke nicht auf die absolute Grösse, sondern auf das specifische Gewicht der Theilchen an. Deshalb verfuhren wir in folgender Weise: in einem kleinen Zimmer wurden die beiden, mit einander gemischten Staubsorten kräftig ausgeklopft; nach 10 bis 15 Minuten hatte sich die Hauptmasse des so entstandenen Staubes bereits wieder zu Boden gesenkt; diese wurde nun sofort entfernt und

1 Ausserdem benützte ich den Staub aus einer Bibliothek, auch hier nur solchen, der sich über der genannten Höhe abgelagert hatte.

Sehr viel Staub findet sich auch, wie ja bekannt, auf den Oefen; doch ist derselbe für unsere Zwecke weniger brauchbar, weil ihm meist Lehmtheilchen beigemischt sind. 
dann der Fussboden des Zimmers mit dickem Papier (Packpapier) belegt; nach 18 bis 24 Stunden, während welcher Zeit das Zimmer von Niemandem betreten worden war, fand sich auf dem Papier eine ganz dünne Schicht feinsten Staubes vor, der nun langsam und vorsichtig zusammengekehrt und gesammelt wurde.

Dieses Verfahren ist freilich unbequem in seiner Ausführung und wenig ergiebig: wir brauchten 14 Tage, ehe eine zu zwei Verstäubungen hinreichende Menge gesammelt war. Aber es ist unzweifelhaft ein sicherer Weg, um solchen Staub zu erhalten, der wirklich schon längere Zeit in der Luft geschwebt hat. Die Versuche haben gezeigt, dass dieses Material in der That leichter ist und daher länger in der Luft schweben bleibt, als der Schulstaub; leider konnten nicht mehrere Versuche mit demselben oder mit noch anderen Staubsorten angestellt werden, da das Versuchszimmer nothwendig für andere Zwecke gebraucht wurde.

Endlich wurden noch zwei Versuche mit Sporen von Aspergillus niger gemacht; aus dem eben genannten Grunde war auch hier eine weitere Fortsetzung derselben nicht möglich.

Die Versuche mit dem Fabrikstaub und den Schimmelpilzsporen hatte Herr Dr. Bitter die Güte auszuführen, da ich durch meinen Fortgang von Bresiau daran verhindert war.

Die Zubereitung des Verstäubungs-Materials.

Wir hätten nun den gesammelten Staub ohne Weiteres in der Luft des Versuchszimmers vertheilen, die damit in die Luft gelangten Keime zählen und dann die Abnahme derselben unter dem Einfluss der Ventilation u. s. w. beobachten können. Da man aber von vornherein annehmen darf, dass der Keimgehalt des Staubes ein recht ungleichmässiger ist, da es ferner bei diesem Verfahren nicht möglich gewesen wäre, zu entscheiden, wie viele der von uns gezählten Bacterien während der Ventilationsversuche von aussen in die Zimmerluft hineingelangt waren, so erschien es zweckmässiger, den Staub zunächst zu sterilisiren und mit einer bestimmten, in der Luft nicht vorkommenden Bacterienart zu imprägniren, darauf wieder zu trocknen und nun erst zu den Versuchen zu benützen.

Behufs Sterilisation wurde der Staub in hermetisch verschlossenen Glasbüchsen 6 bis 8 Stunden lang im Dampfofen auf $100^{\circ}$ erbitzt. Eine so lange Einwirkung dieser Temperatur ist deshalb nöthig, weil sich, wie Vorversuche ergaben, in dem von uns verwendeten Staube äusserst resistente Sporen fanden, welche selbst nach einem $4^{1} / 2$ stündigen Aufenthalt im Dampfofen noch entwickelungsfähig bleiben. ${ }^{1}$

1 Versucht man die Sterilisation im Trockenofen bei höherer Temperatur, so tritt sehr leicht ein theilweises Verkohlen des Staubes ein. Zur Abkürzung der oben genannten Erhitzungsdauer wäre daher die Anwendung des Autoclaven zu empfehlen. 
Einfluss dèr Ventmation aUf den Keimgehalt der Loft. 53

Es handelte sich nun darum, einen zur Imprägnation des Staubes geeigneten Mikroorganismus zu finden. Derstlbe musste offenbar folgenden Bedingungen genügen:

1. er musste, um später in verstäubbaren Zustand übergeführt werden zu können, das Eintrocknen vertragen;

2. er durfte in der Luft für gewöhnlich nicht vorkommen;

3. er durfte nicht pathogen sein;

4. er musste in seinem morphologischen Verhalten oder in der Art seines Wachsthums charakteristisch sein, um leicht von den in der Luft rorkommenden Keimen oder von zufälligen Verunreinigungen unterschieden werden zu können.

Alle diese Anforderungen erfüllt der Bacillus Megaterium; ${ }^{1}$ wegen seiner ungewöhnlichen Grösse ist er bei mikroskopischer Untersuchung mit anderen Bacterienarten kaum zu verwechseln; übrigens sind auch seine Colonieen von denen der gewöhnlichen Luftbacterien - wenigstens derjenigen, die mir bei meinen Versuchen vorgekommen sind - nach einiger Uebung leicht $\mathrm{zu}$ unterscheiden.

Zur Imprägnation des Staubes verwandte ich Reinculturen in $1 / 2$ bis 1 procent. Fleischextract-Lösung, die theils bei $22^{\circ}$, theils bei $35^{\circ}$ gehalten wurden. Schon nach 2 bis 3 Tagen bilden sich Sporen aus und nach etwa 14 Tagen sind die vegetativen Formen fast völlig verschwunden. Die Nährlösungen sind theils gleichmässig getrübt, theils bilden sich Flocken, die sich zu Boden senken; doch lassen sich letztere durch Schütteln leicht vertheilen. Allerdings findet man nicht selten bei der mikroskopischen Untersuchung von solchen Culturen, die fast nur noch Sporen enthalten, grössere, zusammenhängende Complexe derselben, - ein Umstand, auf den wir später noch zurückkommen müssen.

Nachdem die Reinheit der Culturen in jedem Falle durch mikroskopische Untersuchung geprüft war, wurde der sterilisirte Staub mit der Culturflüssigkeit in einem sterilisirten Porcellanmörser verrieben; das Mengenverhältniss von Staub und Flüssigkeit wurde so gewählt, dass das imprägnirte Material die Consistenz eines mässig dicken Breies bekam; dies lässt sich nach einigem Probieren unschwer erreichen.

${ }^{1}$ Derselbe wurde von de Bary (s. Vergleichende Morphologie der Pilze, 1884, S. 499) zuerst auf gekochten Kohlblättern beobachtet. Die einzelnen Bacillen sind etwa $2 \cdot 5 \mu$ breit (also über doppelt so breit wie Milzbrandbacillen), und 4 bis 6 mal so lang als breit; sie zeigen eine langsame Eigenbewegung, bilden oft Ketten von nicht sehr beträchtlicher Gliederzahl und zeigen exquisite Sporenbildung. 
Alsdann wurde das Material auf vorher geglühte, feinmaschige Eisendrahtnetze gebracht und unter der Luftpumpe über Chlorcalcium. getrocknet. Schon nach 36 bis 48 Stunden war dasselbe in verstäubungsfähigem Zustande. Nun wurde es mit einem sterilisirten Ylesser von den Drahtnetzen abgeschabt, im Porcellanmörser wieder fein zerrieben und bis zum Gebrauch in Glasgefässen mit Watteverschluss aufbewahrt. - Weit einfacher war die Herstellung des Schimmelpilzmaterials. Der Aspergillus niger wurde auf Brodbrei gezüchtet, die Cultur von demselben abgekratzt, unter der Luftpumpe getrocknet und dann direct in den Verstäubungsapparat gebracht.

\section{Die Verstäubung.}

Zur Vertheilung des Staubes in der Luft des Versuchszimmers benützte ich einen Pulverzerstäuber, wie er jetzt von den Chirurgen zum Verstäuben von Jodoform u. s. w. viel angewandt wird, und zwar eine Form, bei welcher die comprimirte Luft einen Kautschulsschlauch von etwa $3 / k^{m}$ Länge zu passiren hat, ehe sie in das mit dem zu verstäubenden Material angefüllte Glasgefäss gelangt; ${ }^{1}$ in diesen Schlauch wurde ein kurzes, mit Wattepfropf versehenes Glasrohr eingeschaltet, und auf diese Weise die in der hindurchgetriebenen Luft enthaltenen Keime zurückgehalten. Das Glasgefäss wurde vorher durch trockne Hitze, die Kautschuktheile durch Sublimatlösung, die dann durch Alkohol und steriles Wasser entfernt wurde, sterilisirt.

Die Verstäubung wurde dann möglichst gleichmässig im ganzen Zimmer vorgenommen; zur besseren Vertheilung, namentlich auch in verticaler Richtung, wurde gleichzeitig ein grosser, japanesischer Fächer langsam hin- und herbewegt. Die Versuchsresultate ergaben, dass dieses einfache Verfahren völlig hinreicht, um eine annähernd gleichmässige Vertheilung des Staubes zu erzielen. Die Dauer einer Verstïubung betrug 10 bis 15 Minuten.

\section{Die Zählung der Luftkeime.}

Zur quantitativen Bestimmung der in der Zimmerluft verstäubten Bacterien benützte ich die von Petri (a. a. 0.) sorgfältig ausgearbeitete Methode der Sandfilter. Sie beruht auf der schon seit einiger Zeit bekannten ${ }^{2}$ Thatsache, dass Kies- oder Sandschichten von mässiger Dicke sämmtliche Keime aus der durch sie hindurchgeleiteten Luft zurückzuhalten vermögen.

1 In dem Cataloge ron H. Härtel (Breslau) als Zerstäuber nach Kabierske bezeichnet.

${ }^{2}$ Naegeli (Ontersuchungen über niedere Pilze, S. 127) fand bereits im Jahre 1873, dass Luft, welche durch Kies hindurchgesogen, hierdurch keimfrei gemacht wird. 
Einfluss der Ventilation aUf den KeImgehalt der LUfT. 55

Bei der Anfertigung der Filter habe ich mich im Wesentlichen an Petri's Angaben gehalten; ich benützte Glasröhren von ca. 9 cm Länge und $1.8 \mathrm{~cm}$ Durchmesser, in wolche je zwei, durch Drahtnetze gestützte Sandfilter von $3 \mathrm{~cm}$ Länge eingefügt waren.

Zur Aspiration der Luft benützte ich Flaschen von 6 Liter Inhalt, welche zu je zweien durch Glasröhren und Gummischläuche derart mit einander verbunden waren, dass sich stets der Inhalt der einen in die andere durch Heberwirkung entleerte, und somit die Vertauschung der Plätze der Flaschen, sowie eine Umschaltung der zum Sandfilter führenden Leitung genügten, um sofort eine neue Bestimmung in Gang zu setzen. Die Aspiratoren waren in dem neben dem Versuchsraume gelegenen Zimmer aufgestellt; die Verbindung mit den Sandfiltern erfolgte durch Bleiröhren, welche durch die Wand hindurchgelegt waren. Vor Beginn und am Ende jeder Bestimmung musste das Versuchszimmer betreten werden, um die Wattepfropfen von den Filtern zu entfernen, resp. wieder aufzusetzen; in der Zwischenzeit wurden dieselben auf einem geglühten Drahtnetz aufbewahrt.

Die offene Mündung der Filter war nach oben gerichtet. Meist wurden durch ein Filter 12 Liter Luft hindurchgesogen; die dazu erforderliche Zeit betrug 5 bis 6 Minuten; hieraus und aus dem Durchmesser

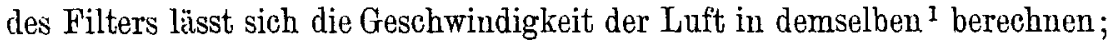
man findet dieselbe (c) nach folgender, leicht abzuleitender Formel:

$$
c=\frac{v}{r^{2} \cdot \pi \cdot t},
$$

wo

$v$ das hindurchgesogene Luftvolumen $\left({ }^{\mathrm{c} m}\right)$,

$r$ den halben Durchmesser des Filters ( $\left.{ }^{\mathrm{cm}}\right)$,

$t$ die Zeit (Sec.)

bedeutet. So finden wir z. B. für:

$$
\begin{aligned}
& v=12,000, \quad r=0 \cdot 9, \quad t=6 \times 60=360 \\
& c=\frac{12,000}{0 \cdot 81 \cdot 3 \cdot 14 \cdot 360}=13 \cdot 1^{\mathrm{cm}} \text { in der Secunde. }
\end{aligned}
$$

Die Korngrösse des für die Herstellung der Filter verwendeten Sandes betrug 0.5 bis $1 \mathrm{~mm}^{2}$ Petri, hat meist mit einer Korngrösse von 0.25

${ }^{1}$ Allerdings bezieht sich die so berechnete Geschwindigkeit nur auf den aicht von Sand erfüllten Theil des Filterröhrchens, da nur in diesem der Luft ein Querschnitt von $r^{2} \pi$ zur Verfügung steht. In dem Sande selbst dagegen muss die Geschwindigkeit wegen der sehr starken Verengerung des von der Luft passirten Querschnittes eine ausserordentlich viel grössere sein.

Diese Bemerkung gilt natürlich auch für die Geschwindigkeitsangaben von Petri.

2 Eine noch geringere Korngrösse hätte den Widerstand dex Sandfilter erhöht und daher eine längere Dauer der einzelnen Luftentnahme bedingt. 
bis $0.5^{\mathrm{mm}}$ gearbeitet, giebt jedoch selbst an, dass auch eine solche von 0.5 bis $1 \mathrm{~mm}$ bereits völlig ausreicht, damit sämmtliche Keime oder wenigstens die ganz überwiegende Mehrzahl derselben schon in dem ersten Sandfilter zurückgehalten werden; da bei meinen Versuchen die Luft mit bedeutend geringerer Geschwindigkeit aspirirt wurde, als bei denjenigen Petri's, ${ }^{1}$ so musste dies um so sicherer der Fall sein. In der That blieben die Platten, auf welche ich den Sand des zweiten Filters ausgoss, entweder ganz steril oder es wuchsen nur sehr wenige Colonieen auf denselben, was das Versuchsresultat nicht beeinflussen konnte. Deshalb sah ich später ganz davon ab, das zweite Filter auszugiessen; das erste wurde meist auf drei, selten auf zwei oder vier Schalen vertheilt. Die Vertheilung erfolgte meist wenige Stunden nach dem Versuch, zuweilen erst am nächsten Tage.

Da der Bac. Megaterium die gewöhnliche Nährgelatine energisch verHüssigt - was die Zählung der Colonieen erschwert oder sogar unmöglich macht, bediente ich mich als Nährbodens eines Gemisches von Agar-Agar $\left(1 \frac{1}{2}\right.$ Procent) und Gelatine (21/2 Procent). ${ }^{2}$ Vor der Anwendung des Agar-Agar allein hatte dieses Gemisch den Vorzug grösserer Transparenz, wodurch natürlich die Zählung und Erkennung tief zwischen den Sandkörnern gelegener Colonieen erleichtert wird. Ausserdem hat das Gemisch nicht, oder doch nur in unbedeutendem Maasse die bei reinem Agar-Agar oft sehr störend wirkende Eigenschaft, bei $35^{\circ} \mathrm{C}$. Wasser auszupressen. Um eine möglichst vollständige Ablösung der Keime von den Sindköruern zu bewirken, wurden die letzteren in dem noch flüssigen Nährmaterial umhergerührt; dazu benützte ich starke Platindrähte, die zu einer Oese umgebogen und selbstverständlich vor dem jedesmaligen Gebrauche geglüht wurden. Damit die Agar-Gelatine während dieses Umrührens nicht zu schnell erstarrte, setzte ich die Culturschalen auf einen mit Wasser gefüllten Hlachen Blechkasten, der vorher auf ca. $40^{\circ} \mathrm{C}$. erwärmt war. ${ }^{3}$

Nach dem Erstarren wurden die Culturen in einen Brütofen von $35^{\circ} \mathrm{C}$. gebracht. Schon nach 36 Stunden waren sämmtliche MegateriumColonieen sehr gut zählbar, die oberflächlichen hatten zu dieser Zeit bereits eine recht stattliche Grösse erlangt. So konnte denn jeder Versuch schon nach zwei Tugen ausgezählt werden ;* dies geschah mit Hülfe eines Zählbretts.

${ }^{1}$ A. a. 0. S. 59.

${ }^{2}$ Dasselbe wird bei einer Temperatur von etwa $95^{\circ}$ flüssig und erstarrt bei $35^{\circ}$.

${ }^{3}$ Durch eine in dom Deckel des Blechkastens befindliche Oeffnung konnte ein Thermometer in das Wasser gebracht werden.

${ }^{4}$ Das Auswachsenlassen der Colonieen bei höherer Temperatur bot ansserdem noch den Vortheil, dass dadurch die Entwickelung von Penicilliumkeimen, die in der 
EINeluss der Ventilation auf Den Kemgenalt Der LufT. 57

Ich muss hierbei noch einer Erscheinung gedenken, deren Deutung für die Zählung der Colonieen von Wichtigkeit ist. Nicht seiten kamen nämlich auf den Platten grössere und kleinere, theils oberflächliche, theils tiefgelegene Complexe aus dicht gedrängten, z. Th. confluirten MegateriumColouieen zur Beobachtung. Theils entstanden dieselben wahrscheinlich durch Ausscheidung von Condensationswasser, theils erklärt sich ihr Auftreten wohl daraus, dass sich, wie oben erwähnt, in den FleischextractCulturen zuweilen Complexe von Sporen vorfanden, die dann bei der Imprägnation des Staubes nicht immer genügend getrennt wurden. Welches nun auch der Ursprung dieser Colonieencomplexe sein mag, jedenfalls wörc es nicht richtig gewesen, ihre einzelnen Colonieen da, wo dies überhaupt möglich war, auszuzählen; deshalb habe ich unten das Auftreten von Complexen stets besonders angegeben.

\section{Untersuchung von Tapeten, Kleiderstoffen $\mathfrak{u}$. s. w.}

Hierbei wurde ganz ähnlich verfahren, wie bei der Untersuchung des Fussbodens (S.49). Ich schnitt mir kleine, quadratische Stückchen ( $2 \mathrm{~cm}$ Scitenlänge) des betreffenden Materials zurecht, sterilisirte sie im Dampfofen und bestïubte sie, nachdem sie wieder getrocknet waren, mit dem Megateriummaterial. Dann wurden sie auf sterilisirter Unterlage mittelst Stecknadeln fixirt, die Tapetenstückchen an der Wand des Versuchszimmers, die Stoff- und Leinwandproben auf einem Tisch. Vor und nach der Einwirkung der Ventilation entnahm ich Proben und brachte sie vorsichtig, um jede Ablösung von Staubtheilchen zu vermeilen, in Culturschalen; hier wurden sie später mit Agar-Gelatine übergossen und in derselben vor dem Lrstarren mittelst sterilisirter Pincette hin- und herbewegt.

\section{Versuchs-Frgebnisse.}

Vorbemerkung. Die Sandfilter befanden sich, wenn nicht anders angegeben, in einer Höhe von $1.2^{\mathrm{m}}$ über dem Fussboden. Die entnommene Luftmenge betrug meist 12 Liter, in vereinzelten Bestimmungen nur 6; die bei den letzteren gewonnenen Zahlen sind, um mit den übrigen vergleichbar zu sein, mit 2 multiplicirt. Ausser in den Vorversuchen wurde, wie schon oben bemerkt, stets nur das erste Filter jedes Röhrchens auf Schaleu vertheilt. Im Folgenden sind die Zahlen der auf den einzeluen Schalen gewachsenen Colonieen bereits addirt. Wenn einige Colonieen

Inft relativ zahlreich enthalten sind, gehindert warde. Bei einer Bestimmung, welche in einer der Lufteintritts-Oeffnungen gemacht wurde, und die ich bei $20^{\circ}$ auswachsen liess, fanden sich in 12 Litern Luft 17 Schimmel- (meist Penicillium) und zwei Bacterien-Colonieen. 
einer anderen Bacterienart angehörten, als Megaterium, so ist dies in Klammern hinzugefügt. Die Zeitangaben beziehen sich auf den Beginn der einzelnen Bestimmungen, und zwar ist stets die Zahl der seit Beendigung der Verstäubung verflossenen Minuten angegeben. Bei den Ventilationsversuchen ist die seit Ingangsetzen der Ventilation verflossene Zeit in Klammern beigefügt.

\section{Absetzenlassen der Keime.}

Versuche mit Schulstaub.

I. Zwei Sandfilter nahe der Zimmermitte aufgestellt; die Bestimmungen wurden abwechselnd an beiden Stellen vorgenommen, und zwar mit Filter I, III, V, VII an der einen, mit Filter II, IV, VI an der anderen.

\begin{tabular}{c|c|r|c|c}
\hline Filter-Nr. & Colonieen & Zeit & Filter-Nr. & Colonieen \\
\hline I & 629 & 0 & & \\
& & 2 & II & 805 \\
III & 73 & 11 & & \\
& & 20 & IV & 51 \\
V & 63 & 35 & & \\
& & 58 & VI & 30 \\
VII & 0 & 270 & &
\end{tabular}

Bei diesem Versuche wurde gleichzeitig nachgesehen, ob sich eine Vermehrung der Keime auf dem Fussboden in Folge des Absetzens aus der Luft nachweisen lässt. Es wurden an drei Stellen des Zimmers die oben beschriebenen Glasplatten mit den Holztäfelchen eingelegt und verschiedene Zeit nach der Verstäubung Proben entnommen. Indess zeigte sich, dass die Vertheilung des Staubes auch auf dicht neben einander gelegenen Täfelchen nicht gleichmässig genug war, um eine sichere Beurtheilung in Bezug auf eine etwaige Zunahme der Keimmenge zu gestatten. So fanden sich z. B. an zwei Stellen des Zimmers bei der Entnahme von je zwei Täfelchen:

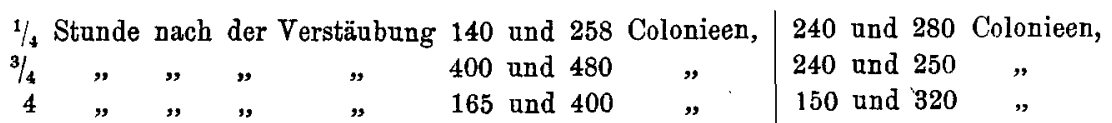

Durch eine einfache Ueberlegung lässt sich zeigen, dass die zu erwartenden Ausschläge bei dieser Versuchsanordnung so gering sind, dass sie innerhalb der Schwankungen in der Vertheilung des Staubes liegen. Ueber jedem Täfelchen von $4^{\mathrm{qcm}}$ Oberfläche befindet sich, da die Ḧ̈he des Zimmers $2.85^{\mathrm{m}}$ beträgt, eine Luftsäule von $0.0011^{\mathrm{cbm}}=1.1$ Liter 
Einfluss der Ventilation auf den Keimgehalt der Luft. 59

Inhalt. Nun waren zu Beginn des Versuches in 12 Liter Luft $6-800$ Keime, in 1.1 Liter also 55-72 Keime enthalten $(1 / 4$ Stunde nachher sogar schon beträchtlich weniger), während die Keimmengen auf zwei dicht neben einander gelegenen Täfelchen zuweilen Differenzen um über 200 zeigten.

Besser lässt sich das allmähliche Senken der Keime durch gleichzeitige Untersuchung in verschiedenen Höhen demonstriren, wie es folgender Versuch zeigt:

II. An zwei vertical über einander gelegenen Stellen des Zimmers werden in Höhen von 0.7 und $2 \cdot 4^{\mathrm{m}}$ über dem Fussboden Sindfilter angebracht.

\begin{tabular}{c|l|c|c|c}
\hline Filter-Nr. & $\begin{array}{c}\text { Obere } \\
\text { Entnahmestelle }\end{array}$ & Zeit & Filter-Nr. & Untere Entnahmestelle \\
\hline I & 170 & 0 & II & 110. \\
III & 19 & 10 & IV & 56 u. ein grösserer tiefer Complex \\
V & 7 & 30 & VI & 23 u. mehrere oberfl. Complexe \\
VII & 8 (3 nicht Meg.) & 60 & VIII & 19
\end{tabular}

Als weitere Belege für das schnelle Absetzen der von uns suspendirten Keime bei ruhiger Luft mögen noch folgende zwei Versuche dienen.

III. Entnahme in der Mitte des Zimmers.

Gegen Ende der Verstäubung: über 300 einzelne Colonieen und mehrere Complexe. 5 Min. nach beendeter Verstäubung: 215 einzel. Col. u. ein grosser oberflächl. Complex, 35 " , , ", 38 Colonieen,

$60, \quad " \quad, \quad$ " $\quad 12$ Colonieen und 1 Complex.

IV. Entnahme wie bei III. Geringere Aussaat.

\begin{tabular}{r|c}
\hline Zeit & Colonieen \\
\hline 0 & 40 und 1 tiefer Complex \\
36 & 5 (4 nicht Megat.) \\
80 & 0 \\
132 & 4 (2 nicht Megat.)
\end{tabular}

Das von uns angewandte Material senkt sich somit zum grössten Theile schon in den ersten 20-30 Minuten nieder; nach $1 \frac{1}{2}$ Stunden enthält die Luft nur noch sehr wenige Keime; wartet man noch länger, so findet man sie meist vollständig keimfrei. 
Dafür, dass sich die unter natürlichen Verhältnissen in der Luft vorkommendeu Mikroorganismen in dieser Beziehung ähnlich verhalten, wie die von uns lünstlich verstäubten, spricht die bereits von Hesse u. A. constatirte Thatsache, dass die Luft in Zimmern, in denen kein Staub aufgewirbelt wird, nahezu keimfrei ist. Auch ich konnte dies nur bestätigen. Eine Bestimmung in dem Versuchszimmer, nachdem dasselbe einige Stunden lang von Niemandem betreten worden war, ergab in 12 Liter Luft nur einen Bacterienkeim. ${ }^{1}$ Ein anderes Mal, nachdem in dem Zimmer bereits mehrfach und ohne besondere Vorsicht. hin- und hergegangen worden war, fanden sich bei zwei gleichzeitigen Bestimmungen 8 resp. 14 Keime in 12 Litern. Nachdem durch Kehren des Zimmers Staub, der sich von früheren Versuchen auf dem Boden abgesetzt hatte, aufgewirbelt worden war, fanden sich nuumehr in derselben Luftmenge 72 resp. 74 Keime.

Versuch mit dem Fabrikstaub.

V. Anordnung wie bei Nr. I. Sehr reichliche Aussaat.

\begin{tabular}{c|c|c|c|c}
\hline Filter-Nr. & Colonieen & Zeit & Filter-Nr. & Colonicen \\
\hline I & 3860 & 0 & II & 3870 \\
III & 1661 & 25 & IV & 1009 \\
V & 456 & 50 & VI & 756 \\
VII & 576 & 70 & VIII & 578 \\
IX & 72 & 120 & X & 78
\end{tabular}

Das Absetzen der an diesem leichteren Material haftenden Keime erfolgt also beträchtlich langsamer, als bei den Versuchen mit Schulstaub; aber auch hier hat sich bereits nach 25 Minuten weit mehr als die Hälfte zu Boden gesenkt.

Nach welcher Zeit völlige Keimfreiheit eintritt, konnte leider nicht festgestellt werden, da es, wie oben erwähnt, nicht möglich war, weitere Versuche mit diesem Material anzustellen.

Versuch mit Sporen von Aspergillus niger.'

VI. Der Sand jedes Filters wurde auf vier Schalen vertheilt; dieselben sind der Reihe nach mit $a, b, c, d$ bezeichnet. Bei der Verstäubung gelangten so grosse Mengen der Sporen in die Luft, dass die Zählung recht schwierig war; auch konnte dieselbe nur ungenau sein, weil nur die oberflächlichen Colonieen berücksichtigt werden konnten, während es nicht

1 Etwa vorhandene Penicillium-Keime konnten allerdings, da die Platten bei $35^{\circ}$. gehalten wurden, nicht zur Entwickelung kommen. 
Einfluss der Ventilation aUf den Kemgehalt Der LUfT. 61

möglich war, etwaige, innerhalb des Nährbodens (Agar-Gelatine) entstandene Mycelien mit Sicherheit zu erkennen. Wenn die Zahl der Colonieen auf einer Platte 3000 überstieg, so war eine Zählung überhaupt nicht mehr möglich, und ist dies durch $\infty$ angedeutet. Um die Abnahme des Keimgehaltes deutlicher hervortreten zu lassen, sind die Resultate der einzelnen Platten nicht summirt worden. Anordnung wie beim vorigen Versuch.

\begin{tabular}{|c|c|c|c|c|c|c|c|c|c|c|}
\hline \multirow{2}{*}{ Filter-Nr. } & \multicolumn{4}{|c|}{ Platten } & \multirow{2}{*}{ Zeit } & \multirow{2}{*}{ Filter-Nr. } & \multicolumn{4}{|c|}{ Platten } \\
\hline & $a$ & $b$ & $c$ & $d$ & & & $a$ & $b$ & $c$ & $d$ \\
\hline I & $\infty$ & $\infty$ & $\infty$ & $\infty$ & 0 & & & & & \\
\hline II & $\infty$ & $\infty$ & $\infty 0^{\circ}$ & 1425 & 25 & III & $\infty$ & $\infty$ & $\infty$ & ca. 2000 \\
\hline IV $^{1}$ & $\infty$ & $\infty$ & $\infty$ & & 45 & $\mathrm{~V}$ & $\infty$ & $\infty$ & $\infty$ & $2-3000$ \\
\hline VI & $2-3000$ & 1000 & 1500 & 800 & 60 & & & & & \\
\hline VII & $2-3000$ & 1000 & $12-1500$ & 680 & 120 & VIII & 1000 & $12-1500$ & 850 & 900 \\
\hline
\end{tabular}

Auch hier ist jedenfalls eine deutliche continuirliche Abnahme der Keime zu constatiren, dje wahrscheinlich noch langsamer erfolgt als bei dem Fabrikstaub; mit Sicherheit ist dies allerdings nach den beiden vorstehenden Versuchen nicht zu entscheiden.

\section{Versuche mit Ventilation.}

Sofort nach dem Ende der Verstäubung wurde eine I uftbestimmung vorgenommen und bald nath Beendigung derselben die Ventilation in Gang gesetzt. Bis auf Nr. XIII und XIV wurden sïmmtliche Versuche mit Schulstaub angestellt.

\section{A. Versuche mit gewöhnlicher Ventilations-Grösse.}

(1-3 malige Lufterneuerung in der Stunde.)

VII. Sommer-Ventilation: $1 \cdot 8$ fache Lufterneuerung in der Stunde. Iufteintritt durch die vier unteren stark verengten Oeffnungen. Iuftaustritt durch den oberen Wasserventilator und einen der oberen Gasventilatoren. Luftentnahme in der Mitte des Zimmers. Beginn der Ventilation 6 Minuten nach dem Ende der Verstäubung.

\begin{tabular}{c|c}
\hline Zeit & \\
\hline 0 & 260 und ein grosser Complex \\
$7(1)$ & 152 \\
$15(9)$ & 60 und einige oberflächliche Complexe \\
$23(17)$ & 38 \\
$45(39)$ & 20 \\
$60(54)$ & 23 \\
$90(84)$ & 10 und ein kleiner Complex
\end{tabular}

\footnotetext{
1 Nur auf 3 Schalen vertheilt.
} 
Ein beschleunigender Einfluss der Ventilation auf die Entfernung der Keime aus der Luft ist aus diesen Zahlen nicht zu erkennen.

Bald nach Beginn der Ventilation wurden auch in den beiden Ausströmungsöffuungen Bestimmungen gemacht.

In dem oberen Gasventilator betrug die Geschwindigkeit im Mittel aus mehreren Messungen $38^{\mathrm{m}}$ in der Minute oder $0.63^{\mathrm{m}}$ in der Secunde. In 12 Litern Luft fanden sich 32 Keime, zum grüssten Theile Megaterium.

In dem oberen Wasserventilator betrug die Geschwindigkeit im Mittel $68^{\mathrm{m}}$ in der Minute oder $1 \cdot 13^{\mathrm{m}}$ in der Secunde. In 12 Litern Luft fanden sich 65 Keime.

Es werden also durch die hier vorhandenen Strömungen zwar Keime fortgeführt; aber die Menge derselben ist nicht bedecitend genug, um einen wesentlichen Einfluss auszuüben. Auch nimmt - wie leicht verständlich und durch Bestimmungen bei anderen Ventilationsversuchen, die ich nicht näher mitzutheilen brauche, direct nachgewiesen wurde die Menge der durch die Ventilation fortgeführten Keime sehr rasch ab, indem offenbar der grössere Antheil des Staubes, der Schwere folgend, langsam zu Boden sinkt.

VIII. Sommerventilation; etwa zweimalige Lufterneuerung in der Stunde. Anordnung ähnlich wie beim vorigen Versuch. Beginn der Ventilation 4 Minuten nach dem Ende der Verstäubung.

\begin{tabular}{c|c}
\hline Zeit & Colonieen \\
\hline 0 & 226 \\
$17(13)$ & 68 \\
$40(36)$ & $12(2$ nicht Megat.) \\
$61(57)$ & 14 (3 nicht Megat.)
\end{tabular}

Das Resultat ist im Wesentlichen dasselbe, wie beim vorigen Versuch.

IX. Sommerventilation; etwa dreimalige Erneuerung in der Stunde. Gleichzeitige Bestimmung an zwei Stellen des Zimmers. Beginn der Ventilation 10 Minuten nach dem Ende der Verstäubung.

\begin{tabular}{c|c|c|c|c}
\hline Filter-Nr. & Colonieen & Zeit & Filter-Nr. & Colonieen \\
\hline \hline I & 180 & 0 & II & 280 \\
III & 60 & $19(9)$ & IV & 62 \\
& & $30(20)$ & V & 26 \\
VI & 23 & $35(25)$ & & \\
VII & 8 & $58(48)$ & & \\
VIII & 3(1 nichtMeg.) $)$ & $280(270)$ & &
\end{tabular}


Also auch hier keine merkliche Beschleunigung der Entfernung der Keime; ob das Auftreten von vereinzelten Megaterium-Keimen noch 4 Stunden 40 Minuten nach der Verstäubung auf ein längeres Schwebenbleiben unter dem Einfluss der bei der Ventilation auftretenden Luftströmungen zu beziehen ist, oder ob es sich hierbei um zufällige Verunreinigungen handelt, möchte ich dahingestellt sein lassen.

X. Winterventilation; $\mathbf{2 \cdot 3}$ malige Lufterneuerung in der Stunde. Gleichzeitige Bestimmung an zwei Stellen des Zimmers. Beginn der Ventilation 5 Minuten nach dem Ende der Verstäubung.

\begin{tabular}{c|c|c|c|c}
\hline Filter-Nr. & Colonieen & Zeit & Filter-Nr. & Colonieen \\
\hline I & 1338 & 0 & II & 2076 \\
III & 412 & $8(3)$ & IV & 318 \\
V & 97 & $25(20)$ & VI & 140 \\
VII & 21 & $50(45)$ & VIII & 32 \\
IX & 8 & $65(60)$ & X & 3
\end{tabular}

Hier scheint in der That eine etwas schnellere Entfernung der Keime aus der Luft erfolgt zu sein, als beim blossen Absetzenlassen; trotz der sehr reichlichen Aussaat finden sich 65 Minuten nach dem Ende der Verstäubung nur noch ganz vereinzelte Keime vor. Indess ist der Effect der Ventilation jedenfalls nur sehr unbedeutend. ${ }^{1}$

\section{B. Versuche mit stärkerer Ventilation.}

(4-7malige Lufterneuerung in der Stunde.)

XI. Winterventilation; 4.2 malige Lufterneuerung. Anordnung wie beim vorigen Versuch.

\begin{tabular}{c|r|c|r|r}
\hline Filter-Nr. & Colonieen & Zeit & Filter-Nr. & Colonieen \\
\hline I & 1942 & 0 & II & 2113 \\
III & 840 & $10(5)$ & IV & 510 \\
V & 61 & $27(22)$ & VI & 128 \\
VII & 17 & $52(47)$ & VIII & 11 \\
IX & 2 & $65(60)$ & X & 0
\end{tabular}

1 Dass die Winter-Ventilation in dieser Stärke bereits eine, wenn anch nur geringe Wirkung zeigt, während die Sommer-Ventilation selbst bei 3 facher Lufterneuerung in der Stunde noch gar keinen merklichen Einfluss hat, dürfte vielleicht darin seine Erklärung finden, dass bei der ersteren schräg von oben nach unten gehende I,uftströmungen auftreten, welche also das Senken der Staubtheilehen begünstigen, während die sehräg von unten nach oben verlaufenden Strömungen bei der Somner-Ventilation eher sogar ein längeres Schwebenbleiben derselben begün. stigen. Ferner werden in Folge des allmählichen Sinkens der Keime die oberen 
Hier ist die Wirkung noch etwas deutlicher, als im vorigen Versuch; nach 65 Minuten ergab die eine Bestimmung bereits fast völlige Keimfreiheit, was beim ruhigen Absetzenlassen nicht erreicht wird. Immerhin ist der Effect bei dieser doch schon recht bedeutenden Ventilationsgrösse. noch sehr unbeträchtlich.

XII. Sommerventilation; 4. 4 fache Lufterneuerung. Gleichzeitige Bestimmungen in der Mitte des Zimmers (ungrade Filternummern) und in einer Ecke (grade Filternummern). Beginn der Ventilation 4 Minuten nach dem Ende der Verstäubung.

\begin{tabular}{|c|c|c|c|c|}
\hline Filter-Nr. & Colonieen & Zeit & Filter-Nr. & Colonieen \\
\hline I & 134 & 0 & $\amalg$ & 260 \\
\hline III & 48 & $10(6)$ & IV & 21 \\
\hline $\mathrm{V}$ & 33 und 1 grösserer & $30(26)$ & VI & 28 \\
\hline VII & 5 & $60(56)$ & VIII & $\begin{array}{l}1 \text { oberfl. Complex am Rande } \\
\text { d.Schale. (Verunreinigung?) }\end{array}$ \\
\hline
\end{tabular}

Der Effect ist hier eher noch etwas geringer, als bei dem vorigen Versuch, da die Aussaat bei jenem bedeutend grösser war.

Eine grössere Wirkung zeigte die Ventilation auf den feinen Fabrilistaub, sowie auf die Sporen ron Aspergillus niger; allerdings konnte mit beiden Materialien nur je ein Ventilationsversuch angestellt werden.

XIII. Versuch mit Fabrikstaub; Winterventilation; 4.5 malige Erneuerung in der Stunde. Gleichzeitige Bestimmung an zwei Stellen des Zimmers. Beginn der Ventilation 5 Minuten nach dem Ende der Verstäubung.

\begin{tabular}{c|r|c|r|r}
\hline Filter-Nr. & Colonieen & Zeit & Filter-Nr. & Colonieen \\
\hline \hline I & 3066 & 0 & II & 1796 \\
III & 684 & $10(5)$ & IV & 741 \\
V & 274 & $25(20)$ & VI & 128 \\
VII & 39 & $50(45)$ & VIII & 26 \\
XI & 6 & $65(60)$ & X & 7
\end{tabular}

Ein Vergleich mit dem oben (S. 60) mitgetheilten Absetzversuch zeigt in der That einen deutlichen. Unterschied zu Gunsten der Ventilation; immerhin dauert es auch hier eine Stunde, ehe die Luft nahezu keimfrei wird, obgleich doch die bei diesem Versuch hergestellte Ventilationsgrösse bereits das äusserste Maass des in der Praxis Zulässigen darstellt.

Luftschichten, welche bei der Sommerventilation den Austrittsöffnungen zunächst liegen, viel schneller keimleer als die unteren, so dass auch aus diesem Grunde die Winterventilation etwas besser wirken kann. 
Einfluss der Ventiliation aUf den Keimgehalit deR LUft. 65

XIV. Versuch mit Sporen ron Aspergillus niger. Anordnung ebenso wie beim vorigen Versuch. Vgl. die Bemerkungen bei Versuch VI.

\begin{tabular}{|c|c|c|c|c|c|c|c|c|c|c|}
\hline \multirow{2}{*}{$\begin{array}{c}\text { Filter- } \\
\text { Nr. }\end{array}$} & \multicolumn{4}{|c|}{ Platten } & \multirow{2}{*}{ Zeit } & \multirow{2}{*}{$\begin{array}{c}\text { Filter- } \\
\text { Nr. }\end{array}$} & \multicolumn{4}{|c|}{ Platten } \\
\hline & $a$ & 6 & $c$ & $d$ & & & $a$ & $b$ & $c$ & $d$ \\
\hline I & $\infty$ & $\infty$ & $\infty$ & $\infty$ & 0 & II & $\infty$ & $\infty$ & $\infty$ & $\infty$ \\
\hline III & $\infty$ & $\infty$ & $\infty$ & ca. 2000 & $10(5)$ & IV & $\infty$ & $\infty$ & $\infty$ & ca. 3000 \\
\hline $\mathrm{V}$ & $\infty$ & ea. 2000 & 0 ca. 1000 & ca. 800 & $25(20)$ & VI & 1200 & 700 & $\begin{array}{c}\text { zer- } \\
\text { brochen }\end{array}$ & 500 \\
\hline VII & 1200 & 1000 & 700 & 400 & $50(45)$ & VIII & ca. 1000 & 600 & 900 & 700 \\
\hline IX & 570 & 530 & 580 & 300 & $65(60)$ & $\mathrm{X}$ & 800 & zer- & 200 & 100 \\
\hline
\end{tabular}

Auch hier zeigt sich gegenüber dem Absetzversuch (S. 60) eine deutliche Wirkung der Ventilation; jedoch befanden sich noch nach einstündiger Einwirkung derselben reichliche Sporenmengen in der Zimmerluft.

Geht man mit der Ventilationsgrösse noch weiter in die Höhe, wobej dann freilich bereits ein recht fühlbarer Zug entsteht, so wird der Einfluss der Ventilation auch auf unser gewöhnliches Versuchsmaterial ein bedeutender. Als Beispiel diene folgender Versuch.

$\mathrm{XV}$. Sommerventilation; 7 malige Erneuerung in der Stunde; die vier unteren Eintrittsöffnungen vollständig geöffnet; oberer Wasserventilator und ein oberer Gasventilator in voller Thätigkeit. Gleichzeitige Bestimmung an zwei Stellen des Zimmers; die erste Bestimmung wird gegen Fnde der Verstäubung gemacht, und sofort nach Beendigung der letzteren die Ventilation in Gang gesetzt.

\begin{tabular}{c|c|c|c|c}
\hline Filter-Nr. & Colonieen & Leit & Filter-Nr. & Colonieen \\
\hline \hline I & 1556 & & II & 362 \\
III & 8 und ein tiefer Complex & 15 & & \\
& ron vielen kleinen Colon. & & & \\
IV & 0 & 30 & V & 0 \\
VI & 2 & 60 & VII & 2 (beide nicht Megat.) \\
VIII & 0 & 150 & IX & 0
\end{tabular}

Also bereits nach 15 Minuten eine sehr beträchtliche Abnahme der Keime, nach 30 Minuten vollständige Keimfreiheit.

\section{Versuche mit starker Durchlüftung des Zimmers.}

(Ueber 10 malige Lufterneuerung in der Stunde.)

XVI. Zwei untere und eine obere Eintrittsöffnung geöffnet. Zwei untere und zwei obere Ventilatoren in Thätigkeit. 14 malige Lufterneuerung in der Stunde. Beginn der Ventilation 4 Minuten nach dem Ende der 
Verstäubung. Gleichzeitige Bestimmung in einer Ecke (ungrade Filternummern) und nahe der Wand zwischen den Fenstern (grade Filternummern); beide Stellen sind directen Luftströmen nicht ausgesetzte

\begin{tabular}{c|c|c|c|c}
\hline Filter-Nr. & Colonieen & Zeit & Filter-Nr. & Colonieen \\
\hline \hline I & 115 & 0 & II & 84 \\
III & 14 & $10(6)$ & IV & 13 \\
V & 0 & $25(19)$ & VI & 0
\end{tabular}

XVII. Maximale Ventilation: sämmtliche 8 Eintrittsöffnungen und alle 5 Ventilatoren benützt. Beginn der Ventilation 10 Minuten nach dem Ende der Verstäubung.

\begin{tabular}{c|c}
\hline Zeit & Colonieen \\
\hline 0 & 83 \\
$12(2)$ & 7 \\
$37(27)$ & 2
\end{tabular}

XVIII. Maximale Ventilation; auch die Thüre zum Treppenflur wird geöffnet. Die Aussaat wird gegen Ende der Verstäubung bestimmt, dann sofort mit der Lüftung begonnen.

Aussaat: 620 Colonieen.

2 Min. nach Beginn der Ventilation: 6 "

\section{0}

" " " " $", \quad 1 \quad$,

50 " " " ",$\quad 5 \quad$ " (3 nicht Meg.)

Wie zu erwarten war, führt ein kräftiger Zug in kürzester Zeit die überwiegende Mehrzahl aller Keime aus der Luft fort; höchstens bleiben einige wenige, ganz vereinzelte Megaterium-Keime in derselben zurück. ${ }^{1}$

\section{Versuche mit Entwickelung von Wasserdampf.}

Um zu erfahren, ob die Entwickelung von Wasserdampf ein schnelles zu Boden Sinken der in der Zimmerluft suspendirten Keime bewirkt, wurde in der Mitte des Versuchszimmers ein Autoclav" aufgestellt und angeheizt; nachdem der Dampf eine Spannung von einigen Atmosphären

${ }^{1} \mathrm{Ob}$ es sich hierbei wirklich um ein Zurückbleiben von einzelnen der Anfangs verstäubten Keime oder vielleicht nur um zufällige Verunreinigungen handelt oder endlich, ob durch die starke Durchlüftung eine Ablösung vereinzelter Keime vom Fussboden u. s. w. zu Stande kommt (s. u.), vermag ich nicht mit Sicherheit zu ent. scheiden.

${ }^{2}$ In einem Versuche statt desselben zwei Koch'sche Dampföfen. 
erlangt hatte, wurde die Verstäubung vorgenommen und die Aussaat bestimmt; dann liess ich einige Minuten lang den Dampf durch einen, an die in dem Deckel des Autoclaven befindliche Oeffnung angefügten, dickwandigen Gummischlauch unter einem Druck von etwa 6 Atmosphären ausströmen; da der Schlauch mittelst einer ihn umfassenden, eisernen Klammer leicht dirigirt werden konnte, so liess sich eine gleichmässige Vertheilung des Dampfes im Zimmer unschwer herstellen. Nachdem der Dampf einige Zeit ausgeströmt war, wurden wieder Bestimmungen der Keimmenge gemacht.

Da sich bald herausstellte, dass eine, für die Praxis verwendbare, rasche und vollständige Entfernung der Keime aus der Iuft auf diesem Wege nicht möglich war, so wurden die Versuche nicht weiter fortgeführt. Immerhin war ein allerdings sehr mässiger, beschleunigender Einfluss auf das Absetzen der Keime unverkennbar, wofür ich zum Beleg folgende zwei Versuche anführen möchte:

XIX. Filter mit ungraden Nummern in der Mitte des Zimmers, nahe beim Autoclaven; Filter mit graden Nummern in einer Ecke aufgestellt.

$11^{\mathrm{h}} 44^{\prime}$ Bestimmung der Aussaat am Ende der Verstäubung. ${ }^{1}$

$11^{\mathrm{h}} 50^{\prime}$ bis $12^{\mathrm{h}} 2^{\prime}$ Dampfentwickelung $(6 \mathrm{Atm}$.) mit einmaliger kurzer Unterbrechung.

Es ist die Zeit (Min.) seit dem Ende der Verstäubung angegeben. die seit dem Beginn der Dampfentwickelung in Klammern beigefügt.

\begin{tabular}{c|c|c|c|c}
\hline Filter-Nr. & Colonieen & Zeit & Filter-Nr. & Colonieen \\
\hline I & 150 & 0 & II & 96 \\
III & 49 & $8(2)$ & IV & 19 \\
V & 23 & $19(13)$ & IV & 14 \\
VII & 19 & $40(36)$ & VIII & 7
\end{tabular}

XX. Filter mit ungraden Nummern an der Wand zwischen den Fenstern. Filter mit graden Nummern in einer Ecke.

$12^{\text {h }} 6^{\text {m }}$ Ende der Verstäubung; Bestimmung der Aussaat.

$\left.\begin{array}{lrl}12^{\mathrm{h}} & 8^{\mathrm{m}} \text { bis } 12^{\mathrm{h}} 16^{\mathrm{m}} \\ 12^{\mathrm{h}} 29^{\mathrm{m}} & \text { bis } 12^{\mathrm{h}} 36^{\mathrm{m}}\end{array}\right\}$ Dampfentwickelung.

- Bei diesem und dem folgenden Versuch, sowie bei einigen früheren, wurde der grösseren Schnelligkeit halber die Aussaat nur ans 6 Litern (in 2 bis 21/. Min.) bestimmt und das so gewonnene Resultat durch Verdoppelung mit den späteren Bestimmungen (12 Liter) vergleichbar gemacht. 


\begin{tabular}{c|c|c|c|c}
\hline Filter-Nr. & Colonieen & Zeit & tilter-Nr. & Colonieen \\
\hline I & 246 & 0 & II & 104 \\
III & 32 u. ein tiefer Complex & 11 & IV & 32 u. ein tiefer Complex \\
V & 4 & 30 & VI & 2
\end{tabular}

4. Versuche über die Ablösung von Keimen vom Fussboden, Tapeten, Kleiderstoffen u. s. w.

Die Frage, ob die bei der Ventilation auftretenden Luftströmungen eine Ablösung der Keime vom Fussboden, Tapeten, Möbeln, Kleidern and Wäsche bewirken können, war in doppelter Hinsicht von Interesse. Wenn nämlich eine solche Ablösung in beträchtlichem Maasse stattfand, so konnte die Ventilation auch pathogene Keime, die sich auf dem Fussboden u. s.w. abgelagert hatten, von da fortschaffen; andererseits musste dies aber auch die Gefahr mit sich bringen, dass die durch die Luftströmungen losgelösten und eine Zeit lang suspendirt gehaltenen Keime vor jhrer vollständigen Entfernung aus der Luft des Zimmers eine Infection hervorzurufen im Stande wären.

Die einfache Versuchsanordnung, deren ich mich bediente, ist bereits oben (S. 57) geschildert worden; sie gestattete natürlich nicht, zu entscheiden, ob vereinzelte Keime durch die in Anwendung kommenden Luftströmungen losgerissen werden; dazu ist die Vertheilung des Staubes auch an dicht neben einander gelegenen Stellen nicht gleichmässig genug; aber es liess sich jedenfalls feststellen, ob eine solche Ablösung in nennenswerthem Maasse oder gar nahezu vollständig vor sich ging.

Aus einer grösseren Reihe von Versuchen, die ich zum Theil mit den eigentlichen Ventilationsversuchen verbinden konnte und bei denen die äusseren Bedingungen möglichst variirt wurden, hat sich ergehen, dass selbst durch die stärksten, bei der Ventilation auftretenden Luftströmungen eine irgendwie beträchtliche Ablösung nicht erfolgt.

Zum Belege mögen einige Versuche mitgetheilt werden:

Bei dem Versuch IX (S. 62) mit Sommerventilation, etwa dreimaliger Lufterneuerung in der Stunde, wurden an verschiedenen Stellen des Fussbodens die Glastafeln mit den Holzplättchen eingefügt und vor Beginn der Ventilation, sowie verschiedene Zeit nachher Proben entnommen. An der einen stelle fanden sich z. B.:

Vor Beginn der Ventilation (nach beendeter Verstäubung) ca. 440 und 572 Keime. 40 Minuten nach Beginn der Ventilation . . . . . . ca. 300 und 400 ," $4 \frac{1}{2}$ Stunden , , , $\quad$, . . . . . . ca. 400 und 540 ", 
Finfluss der Ventilation adf den Keimgehalt der Luft. 69

Bei dem Versuch XV (S. 65) mit Sommerventilation, 7 maliger Lufterneuerung in der Stunde, fanden sich an einer Stelle:

Bald nach Beginn der Ventilation: ca. 300 und 480 Keime.

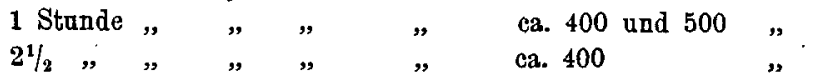

Bei dem Versuch XVIII (S. 66) mit maximaler Durchlüftung wurden in der Mitte des Zimmers und direct hinter der einen Einströmungsöffnung die Holztäfelchen eingelegt.

Es fanden sich auf den entnommenen Proben:

\begin{tabular}{|c|c|c|}
\hline . & $\begin{array}{l}\text { Vor Beginn der } \\
\text { Ventilation }\end{array}$ & $\begin{array}{l}40 \text { Minuten nach } \\
\text { dem Beginn }\end{array}$ \\
\hline $\begin{array}{l}\text { In der Mitte des Zimmers . . . . . } \\
\text { Hinter der Einströmungsöffnung . . . }\end{array}$ & $\begin{array}{l}\text { ca. } 30 \text { u. } 70 \\
\text { ca. } 50 \text { u. } 70\end{array}$ & $\begin{array}{l}\text { ca. } 40 \text { ฉ. } 50 \\
\text { ca. } 50 \text { u. } 70\end{array}$ \\
\hline
\end{tabular}

Gleichzeitig wurden Sammet-, Tuch-, Jute-Stũckchen u. s. w. auf einem im Zimmer aufgestellten Tisch den Luftströmungen in verschiedener Richtung (tangential und senkrecht zur Achse derselben) ausgesetzt. So funden sich z. B.:

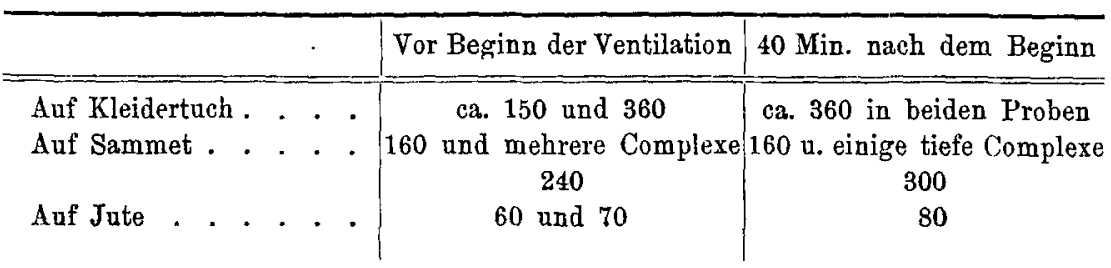

Bei anderen Versuchen derselben Art wurden ähnliche Resultate auch für (an die Wand angeheftete) Tapetenstückchen, ferner für Leinwand und Möbelplüsch gefunden.

Zuweilen fand ich bei den nach Einwirkung der Ventilation entnommenen Proben geringere Werthe als vorher; da aber ebenso oft das Umgekehrte vorkam - wofür die eben mitgetheilten Zahlen schon Belege geben - so dürfte die Annahme berechtigt sein, dass es sich hier nur. um eine ungleichmässige Vertheilung des Staubes handelt; dies ist um so wahrscheinlicher, da sich ja auch bei gleichzeitig entnommenen Proben zuweilen sehr beträchtliche Differenzen zeigen.

Die grösste Luftgeschwindigkeit, welche bei den Ablösungsversuchen angewandt wurde, betrug $130-160^{\mathrm{m}}$ in der Minute oder $2 \cdot 1-2.5^{\mathrm{m}}$ in der Secunde; sie wurde dadurch erreicht, dass sämmtliche Ventilatoren in maximale Thätigkeit gesetzt wurden, während nur eine Eintrittsöffnung offen war; in diese wurden die mit Megaterium-Material bestäubten Holztäfelehen, ferner Stückchen von Leinwand u. s. w. hineingebracht, indem 
sie, wie gewöhnlich, auf einer sterilisirten Unterlage (von Holz) mit Stecknadeln fixirt waren. Es wurden Proben vor und nach einstündiger Einwirkung des Luftzuges entnommen; auch bei diesem Versuch wurde eine irgendwie beträchtliche Loslösung vermisst, wie man aus folgenden Zahlen ersieht:

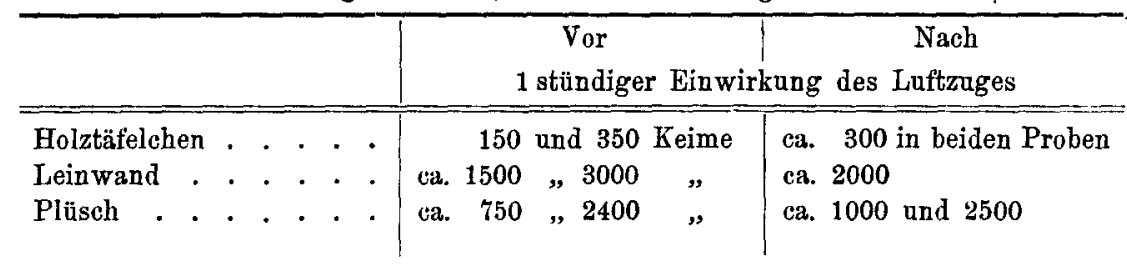

\section{Zusammenfassung und Folgerungen.}

Wemugleich unsere Versuche über den Einfluss der Ventilation auf in der Luft suspendirte Mikroorganismen noch keineswegs als abgeschlossen zu erachten sind, vielmehr eine weitere Fortführung derselben (mit noch anderen Staúbarten u. s. w.) sehr wünschenswerth erscheint, so lassen sich doch schon aus den bisher erreichten Resultaten gewisse Folgerungen ziehen, die zunächst natürlich nur für das von uns benutzte Versuchsmaterial gelten.

Fassen wir die gewonnenen Versuchsergebnisse zusammen:

I. In ruhiger Luft senken sich die von uns verstäubten Keime rasch zu Boden; bei Anwendung feinen Schulstaubes ist die Luft bereits nach $1 \frac{1}{2}$ Stunden nabezu keimfrei. Noch leichteres Material (feinster Woll- und Haderustaub, Schimmelpilz-Sporen) erfordert naturgemäss eine längere Zeit, um sich abzusetzen.

II. Die meistens übliche Ventilationsstärke, welche einer ein-bis dreimaligen Lufterneuerung in der Stunde entspricht, macht die Zimmerluft nicht oder (bei Winterventilation ${ }^{1}$ ) doch nur ganz unwesentlich schneller keimfrei als das blosse $A b$ setzenlassen.

III. Eine weitere Steigerung der Ventilationsgrösse, wie sie aber praktisch, ohne directen Zug hervorzurufen, kaum durchführbar ist, vergrössert allmählich den Einfluss der Ventilation auf die in der Luft schwebenden Keime. Die Grenze. bei welcher eine kräftigere und raschere Wirkung beginnt, dürfte für unser Versuchsmaterial etwa einer sechs-bis siebenmaligen Lufterneuerung in der Stunde entsprechen. ${ }^{2}$

1 Vgl. Versuch X. S. 63.

2 Rietschel (Lüftung und Heizung won Schulen, Berlin 1886) giebt an, diss es noch möglich sei, eine $4 \cdot 5$ malige Erneuerung der Zimmerluft in der Stunde ohne 
Einfluss Der Ventilation aUf den Keimgehalt DeR lufeT. 71

IV. Eine schnelle und vollständige Fortführung der Keime aus der Luft von Wohnräumen lässt sich nur durch kräftigen $\mathrm{Zug}$ erreichen.

V. Eine irgendwie beträchtliche Ablösung von Keimen vom Fussboden, von den Tapeten, Möbeln, Kleiderstoffen u. s. w. erfolgt selbst durch die bei starker Durchlüftung der Zimmer auftretenden Strömungen nicht.

VI. Die Entwickelung von Wasserdampf ist nicht im Stande, in der Luft suspendirte Keime rasch und vollständig niederzuschlagen; jedoch beschleunigt sie das Absetzen derselben in freilich nicht sehr beträchtlichem Maasse.

Inwieweit nun diese Ergebnisse und die aus ihnen zu ziehenden Folgerungen auf die unter natürlichen Verhältnissen in der Luft vorkommenden Krankheitserreger zu übertragen sind, das ist vorläufig mit Sicherheit noch nicht zu entscheiden. Wir kennen ja die Erreger gerade derjenigen Krankheiten, welche nach der ärztlichen Erfahrung am häufigsten und leichtesten durch dje Luft übertragen werden, nämlich der acuten Exantheme, noch gar nicht; aber wir haben auch andererseits einstweilen keinen Grund, anzunehmen, dass sich dieselben in ihrer Grösse und in ihrem Gewicht wesentlich von den bisher bekannten pathogenen Mikroorganismen unterscheiden; und wir werden deshalb mit einem hohen Grade von Wahrscheinlichkeit vermuthen dürfen, dass sie, ebenso wie die gewöhnlichen Mikroorganismen der Luft, an kleinen Staubpartikelchen haften.

Da nun ferner der von uns angewandte Sehulstaub ein Material ist, welches wohl zweifellos unter natürlichen Verhältnissen Luftinfection hervorzurufen im Stande ist, ${ }^{1}$ und da der Staub aus Wohnzimmern und Krankenhäusern im Wesentlichen denselben Ursprung und daher auch dieselbe Zusammensetzung haben muss, wie das von uns verwendete Laterial, ${ }^{2}$ so wird man die an dem letzteren gewonnenen Resultate auch auf praktische Verhältnisse übertragen dürfen, wobei man sich freilich stets bewusst bleiben muss, dass diese Uebertragung nur unter den eben entwickelten Voraussetzungen zu Recht besteht, - Voraus-

Zagempfindung herzustellen. Auch dieses Maximam liegt mithin noch unter der angegebenen Grenze.

1 Dass mit demselben in der That anch pathogene Mikroorganismen von Luftströmungen fortgeführt werden können, liess sich durch Versuche, welche ich zu anderen Zwecken angestellt habe, direct nachweisen.

${ }^{2}$ Wenn sich auch vielleicht in Bezug auf die Zeitdauer des Absetzens und die untere Grenze der Ventilationswirkung kleine Unterschiede herausstellen können. 
setzungen, deren allgemeine Gültigkeit durch weitere F'orschungen erwiesen oder widerlegt werden muss.

Fragen wir uns nun, auf welche Weise wir die suspendirten Keime aus der Luft eines Zimmers entfernen können, so müssen wir wiederum zwei Fälle unterscheiden: erstens die einmalige Desinfection der Luft eines zur Zeit nicht bewohnten Zimmers; zweitens die contin uirliche Entfernung der Keime aus der Luft eines bewohnten Zimmers, in dem Maasse, als sich dieselben z. B. von der Körperoberfläche der Kranken, von den Kleidern u. s. w. ablösen.

Für die Erledigung der ersten Aufgabe haben wir zwei Möglichkeiten: wir können die Keime mit der Luft entfernen oder aus der Luft abscheiden; jenes geschieht durch kräftige Zugluft, dieses durch einfaches Absetzenlassen. Beide Wege sind sicher; der erstgenannte hat den Vorzug: der Schnelligkeit, aber er ist eigentlich nur in einzeln stehenden Baracken u. dgl. anzuwenden. In Wohnhäuseru und Hospitälern dagegen, wo die aus der Zimmerluft fortgeführten pathogenen Keime eventuell nicht direct in's Freie, sondern erst noch in Corridore, Treppenflure u. s. w. gelangen, bietet dieses Verfahren die Möglichkeit einer weiteren Verbreitung der Infectionsträger. - Ausserdem aber ist stets nicht nur die Luft, sondern es sind gleichzeitig Fussboden, Wände, Möbel u. s. w. des Zimmers inficirt; und eine Desinfection dieser Flächen und Gegenstände wird auch durch die stärkste Lüftung in keiner Weise geleistet. Wohl aber ist es möglich - unsere Versuche gestatten nicht, dies mit Sicherheit zu entscheiden -, dass durch die Zugluft vereinzelte, lose sitzende Keime vom Fussboden u. s. w. abgelöst werden, und so die Zimmerluft immer wieder vorübergehend inficirt wird.

Unter diesen Umständen wird deshalb der andere Weg vorzuziehen sein: man wird das betreffende Zimmer mehrere - der Sicherheit halber vielleicht 12 bis 24 - Stunden lang bei verschlossenen Thüren und Fenstern belassen; dann haben sich sämmtliche Keime zu Boden gesenkt und man kann nun das Zimmer vorsichtig betreten und den Fussboden nass - am besten sofort mit $1 \%$ Sublimatlösung - aufwischen, wodurch eine fernere Ablösung von Keimen mit Sicherheit verhindert resp. auch eine sofortige Abtödtung derselben erreicht wird. Alsdann kann man, ohne eine Luftinfection fürchten zu müssen, zur Desinfection der Wände, löbel u. s. w. schreiten.

Für die Erledigung der $\mathrm{z}$ weiten Aufgabe haben uns unsere Versuche keinen sicheren Weg gezeigt. ${ }^{1}$ Die Ventilation in der gewöhn-

${ }^{1}$ In einer jüngst erschienenen Arbeit Cornet's „Dic Prophylaxe der T'uberulluse" (Berliner klinische Wochenschrift, 1889, Nr. 12ff.) findet sich (Nr.13, S. 281) folgender Rath für die Desinfection der Luft in Krankenzimmern: „Ist, beispielsweise 
lich herstellbaren Intensität - bis höchstens 4.5 malige Lufterneuerung in der Stunde - bewirkt sicher keine rasche und vollständige Fortführung. der Mikroorganismen aus der Luft. Noch viel weniger ist sie im Stande, an den Wänden, am Fussboden, an Möbeln und Kleidern haftende Keime von diesen loszulösen und zu entfernen; dies vermögen selbst die bei starker Durchlüftung auftretenden Luftströmungen nicht in irgendwie erheblichem Maasse zu thun.

Wenn somit eine rasche, continuirliche Entfernung der in die Luft übergehenden Keime nicht möglich ist, so wird man in Hospitälern oder Krankenzimmern, in denen sich Patienten mit durch die Luft übertrag. baren Infectionskrankheiten befinden, um so grösseren Werth auf die Prophylaxe legen, d. h. jede Erregung von Staub möglichst vermeiden müssen. Vor Allem ist hier das trockene Aufkehren des Fussbodens, sowie das Abstäuben von Schränken u. s. w. zu widerrathen, da hierbei der grösste Theil der Keime, die sich aus der Luft abgeschieden haben, wieder aufgewirbelt wird. Das einzig Rationelle ist hier das Abwaschen mit einer sicher wirkenden, antiseptischen Lösung ( $1 \%$ Sublimat). Dass Polstermöbel, Teppiche u. s. w. überhaupt nicht in Krankenzimmer gehören, dürfte wohl bereits allgemein anerkannt sein. Das blosse, langsame Hin- und Hergehen auf gedieltem Fussboden bewirkt keinen merklichen Uebergang von Keimen in die Luft; denn, obgleich in unseren Versuchen bei jeder Luftbestimmung ein zweimaliges Betreten des Versuchszimmers nothwendig war und sich auf dem Boden des letzteren ein äusserst keimreicher Staub befand, so erwies sich doch die Luft längere Zeit nach der Verstäubung völlig keimfrei.

Noch in einer anderen Beziehung scheinen die Ergebnisse unserer Versuche nicht ohne praktische Bedeutung zu sein. Seit langer Zeit hat man die Durchlüftung von inficirten Kleidern u. s. w. als ein Mittel angesehen, um die an ihnen haftenden Krankheitskeime zu entfernen, und

beim Ordnen der Betten, eine Staubentwickelung unvermeidbar, so lasse man, besonders, wenn ein Kranker im Zimmer ist, durch einen feinen Wasserspray die Staubpartikelchén alsbald niederschlagen."

Auf welche Erfahrungen sich Cornet bei diesem Vorschlage stützt, ist aus seiner Arbeit nicht ersichtlich. Abgesehen davon, dass die praktische Durchführung der von ihm empfohlenen Massregel auf Schwierigkeiten stossen dürfte, ist auch ihre Wirksamkeit zweifelhaft; ich möchte in dieser Hinsicht auf eine Beobachtung Petri's (a. a. O., S. $63 \mathrm{ff}$., Versuch 9 und 10) verweisen, welcher Gelegenheit hatte, vor und unmittelbar nach einem feinen Sprühregen von etwa einstündiger Dauer Luftuntersuchungen zu machen, und hierbei eine nur geringe Abnahme der in der Luft enthaltenen Keime unter dern Einflusse dieses doch recht ausgiebigen ,Sprays" constatiren konnte.

Aus den schon früher angegebenen äusseren Gründen konnte ich eine experimentelle Prüfung des Cornet'schen Vorschlages nicht mehr vornehmen. 
noch neuerdings ist diese Massregel für solche Ortschaften, welche nicht im Besitz von Desinfectionsapparaten sind, - und das ist doch noch bei der überwiegend grossen Mehrzahl der Fall - vou autoritativęr Seite empfohlen worden. So wird in der Desinfections-Anweisung des preussischen Medicinal-Ministeriums vom 14. Juli 1884, Ziffer 7 ,die dauernde Aussergebrauchstellung und die Durchlüftung der inficirten Gegenstände an einem warmen, trockenen und vor Regen geschützten Orte (unbewohnter Hausboden, Scheuer u. s. w.) " angerathen; und Pistor, ${ }^{1}$ welcher gelegentlich einer Besprechung der vom Berliner Polizeipräsidium im Februar 1887 erlassenen Desinfections-Anweisung auf jene Massregel wiederum hinweist, empfiehlt u. A., den Inhalt inficirter Federbetten und Matratzen auszubreiten und tagelang zu durchlüften.

Nach unseren Versuchen findet selbst durch starke Durchlüftung eine Loslösung der anhaftenden Keime von Kleidern u. s. w. nicht statt. Aueh lehrt die alltägliche Beobachtung, dass selbst stärkere Luftströmungen, wie sie im Freien auftreten, nicht im Stande sind, grob-sichtbare Staubpartikel von Kleiderstoffen zu entfernen - eine Erfahrung, welche mit Fug und Recht auch auf die an den Staubtheilchen haftenden Infectionserreger zu übertragen ist. Wenn daher eine desinficirende Wirkung des Hängenlassens und Durchlüftens beobachtet wird, so könnte diese lediglich auf der Austrocknung der Krankheitskeime beruhen. Da nun aber diejenigen pathogenen Mikroorganismen, welche im Stande sind, Luftinfection hervorzurufen - wie die Tuberkelbacillen und die Erreger der acuten Exantheme - das Austrocknen vertragen, so können diese durch jenes Verfahren nicht beseitigt werden. Eine ausgiebigere Beseitigung des Staubes und auch der Infectionserreger ist durch Klopfen, Bürsten u. s. w. zu erzielen. Aber diese Manipulationen ebenso wie das Ausschütten des Inhalts von inficirten Federbetten und Matratzen sind wegen der damit stets verbundenen Staubentwickelung für die damit beauftragten Personen entschieden bedenklich und können keinesfalls empfohlen werden.

Am Schlusse dieser Arbeit erlaube ich mir, Herrn Prof. Flügge, auf dessen Anregung und mit dessen stetiger, freundlicher Unterstützung ich dieselbe ausgeführt habe, hierfür meinen besten Dank zu sagen.

Auch Hrn. Dr. Bitter, Assistenten am Breslauer hygienischen Institut, bin ich für seine mannigfache Beihülfe bei der Ausführung der vorstehenden Versuche zu grossem Danke verpflichtet.

1 Einige Bemerkungen zu der von dem königl. Polizeipräsidium in Berlin unter dem 7. Februar d. J. erlassenen Anweisung zum Desinfections-Verfahren bei Volkskrankheiten. Deutsche Vierteljahrsschrift für öffentliche Gesundheitspflege. 1887. Bd. XIX. S. 328. 